\title{
Pengukuran Tingkat Kepuasan Pengguna Jasa Parkir di Pusat Pembelanjaan Royal Plaza Surabaya
}

\author{
Mohammad Djaelani' ${ }^{1}$, Didit Darmawan ${ }^{2, *}$ \\ ${ }^{1}$ Fakultas Ekonomi, Manajemen, Universitas Mayjen Sungkono, Mojokerto, Indonesia \\ ${ }^{2}$ Fakultas Teknik, Sipil, Universitas Sunan Giri Surabaya, Sidoarjo, Indonesia \\ Email: ${ }^{1}$ bpk.mohammaddjaelani@gmail.com, 2,"dr.diditdarmawan @ gmail.com \\ Email Penulis Korespondensi: dr.diditdarmawan@gmail.com \\ Submitted: 23/11/2021; Accepted: 29/11/2021; Published: 30/11/2021
}

\begin{abstract}
Abstrak-Tujuan dari studi ini adalah untuk mengetahui tingkat kepuasan pengguna jasa parkir kendaraan di pusat pembelanjaan Royal Plaza Surabaya. Survei ini dilakukan di area parkir Royal Plaza. Data primer dikumpulkan peneliti dari sumber utama yaitu pengguna jasa parkir Royal Plaza dengan cara wawancara dan pengisian kuesioner. Populasi di penelitian ini adalah pengunjung yang pernah menggunakan area parkir Royal Plaza. Sampel adalah pengguna jasa parkir Royal Plaza yang memenuhi syarat sebanyak 100 responden. Temuan dari studi ini adalah responden pada umumnya cenderung telah mencapai kepuasan dalam tingkatan yang baik. Ada beberapa atribut yang perlu dikembangkan lebih baik lagi dan ada atribut yang telah memuaskan pengguna. Atribut yang harus dipertahankan sebagai unsur utama pembentuk kepuasan pengguna jasa parkir adalah akses lokasi parkir telah dekat dengan pusat perbelanjaan dan mereka tidak pernah berputar-putar dalam area parkir untuk mencari tempat parkir. Parkir sudah memenuhi standar keamanan seperti adanya cctv dan mereka merasa kendaraan akan terparkir dengan aman.
\end{abstract}

Kata Kunci: Kepuasan Pengguna Jasa Parkir; Fasilitas Parkir; Pusat Pembelanjaan; Customer Satisfaction Index

\begin{abstract}
The purpose of this study is to determine the level of satisfaction of vehicle parking service users at the Royal Plaza Surabaya shopping center. This survey was conducted in the Royal Plaza parking area. Primary data were collected by researchers from the main source, namely users of Royal Plaza parking services by means of interviews and filling out questionnaires. The population in this study are visitors who have used the Royal Plaza parking area. Samples are users of Royal Plaza parking services who meet the requirements of 100 respondents. The finding of this study is that respondents in general tend to have achieved a good level of satisfaction. There are several attributes that need to be developed better and there are attributes that have satisfied users. The attribute that must be maintained as the main element forming satisfaction of parking service users is that the access to the parking location is close to the shopping center and they never go around in the parking area to find a parking space. Parking has met security standards such as cctv and they feel the vehicle will be parked safely.
\end{abstract}

Keywords: Parking Service User Satisfaction; Parking Facilities; Shopping Centers; Customer Satisfaction Index

\section{PENDAHULUAN}

Salah satu pusat perbelanjaan yang ada di Surabaya adalah Royal Plaza. Ini ada sejak tahun 2006 dan terdiri dari enam lantai. Berbagai tenant terkenal ada di pusat pembelanjaan ini yang memiliki lokasi dengan letak sangat strategis dan mudah dijangkau sehingga keramaian selalu ada.

Royal Plaza mempunyai total luas area $11.500 \mathrm{~m} 2$, total leaseable area $63.000 \mathrm{~m} 2$, dan total gross floor area $130.000 \mathrm{~m} 2$. Ada ketersediaan 2.100 unit/toko. Ketersediaan tempat parkir yang luas telah mempermudah setiap pengunjung. Kapasitas parkir mobil ada 2.000 lot sedangkan kapasitas parkir motor sebanyak 4.000 lot.

Ketersediaan tempat parkir merupakan salah satu daya tarik kunjungan ke pusat pembelanjaan sebagai salah satu pusat aktivitas masyarakat. Daya tarik area dengan tingkat pergerakan barang dan orang yang tinggi, menghasilkan pergerakan rute yang padat di area tersebut. Hal itu mengakibatkan kebutuhan tempat parkir yang lebih luas. Ini membutuhkan wawasan mengenai ruang parkir di pusat perbelanjaan yang berperan sebagai rujukan perencanaaan ruang parkir yang bagus di area serta gedung.

Karakteristik parkir harus teridentifikasi secara tepat dan akurat agar mengetahui elemen penting dalam penilaian pelayanan dan permasalahan parkir. Bagaimana persepsi pengunjung terhadap kondisi perparkiran, volume parkir, lama waktu, penyediaan dan kapasitas ruang parkir. Ini akan memengaruhi kepuasan pengunjung Royal Plaza perihal perilaku mereka tentang parkir. Tujuan dari studi ini adalah untuk mengetahui tingkat kepuasan pengguna jasa parkir kendaraan di pusat pembelanjaan Royal Plaza Surabaya.

\section{METODE PENELITIAN}

Penelitian ini mengarah kepada tingkat kepuasan pengguna jasa parkir. Menurut Zeithaml dan Bitner (1996), jasa diartikan sebagai setiap bentuk kegiatan ekonomi yang bukan berwujud, tidak menghasilkan kepemilikan apa pun serta dikonsumsi secara bersamaan dan memberikan nilai tambah. Jasa parkir salah satu bentuknya.

Menurut Lovelock( 1996), kualitas jasa merupakan analogi antara layanan yang dirasakan pelanggan jasa dengan kualitas layanan yang diharapkan sebelumnya. Menurut Parasuraman et al.( 1985) terdapat 5 ukuran dari kualitas jasa, ialah tangibles, reliability, responsiveness, assurance, serta empathy.

Dimensi tersebut memiliki peran untuk mengetahui harapan pengguna jasa dan kenyataan yang mereka rasakan (Masitoh et al., 2017; Darmawan, 2019). Harapan yang terpenuhi atau melebihi maka dapat dikatakan bahwa mereka telah menerima kualitas jasa secara baik (Anderson \& Olsen, 2008). Ini menyebabkan terbentuknya kepuasan (Cronin 
\& Taylor, 1992). Sebaliknya, ketidakpuasan akan ada bila pengguna jasa tidak dapat terpenuhi harapannya (Darmawan, 2009).

Menurut Kotler dan Armstrong (2016), determinan yang memunculkan kepuasan pengguna jasa perlu diketahui oleh penyedia jasa. Kepuasan atau ketidakpuasana adalah reaksi konsumen kepada penilaian ketidaksuaian yang dialami antara impian saat sebelum memakai serta kemampuan sehabis memakai ataupun konsumsinya (Johnson et al., 2001; Darmawan, 2021). Pengukuran kepuasan bisa diukur lewat sebagian tata cara semacam sistem keluhkesah serta anjuran, survei kepuasan pelanggan, ghost shoping, serta lost customer analysis (Kotler \& Keller, 2016). Ada keterkaitan antara kualitas jasa dan kepuasan pengguna. Beberapa studi telah menyebutkan hal itu seperti Darmawan (2004); Djati (2004); Zameer et al. (2015).

Metode di survei ini adalah deskriptif kuantitatif untuk menjelaskan tingkat kepuasan tempat parkir di pusat perbelanjaan melalui analisis statistik. Survey mengutip sampel dari sesuatu populasi serta memakai angket selaku instrumen pengumpulan informasi. Pengukurannya ditunjukan pada impian serta anggapan konsumen pelayanan parkir.

Survei dilakukan di area parkir Royal Plaza. Data primer didapatkan peneliti dari sumber utama yaitu pengguna jasa parkir Royal Plaza dengan cara wawancara dan pengisian kuesioner. Populasi di penelitian ini adalah pengunjung yang pernah menggunakan area parkir Royal Plaza. Sampel adalah pengguna jasa parkir Royal Plaza yang memenuhi syarat, yaitu berusia 17 tahun lebih, dalam keadaan sadar dan bersedia diwawancarai, telah menggunakan jasa parkir di Royal Plaza, bukan karyawan atau pemilik tenant, dan mengendarai mobil untuk diparkir bukan sebagai penumpangMetode pengumpulan sampel dicoba dengan cara purposive sampling sebab jumlah sampel belum dikenal secara pasti hingga jumlah sampel hendak ditetapkan bersumber pada ketentuan yang ditetapkan serta beralasan tujuan khusus, ialah sebesar 100 responden.

Penyusunan kuesioner bersumber pada pada 5 dimensi kualitas pelayanan dari teori Parasuraman et al. (1985). Ini terdiri dari tangibles, reliability, responsiveness, assurance, serta empathy. Tiap dimensi terbuat 2 persoalan menggantikan arti dari tiap dimensi untuk tanggapan responden dengan pendekatan 5 rasio Likert, ialah sangat setuju dengan angka 5, setuju dengan angka 4, netral dengan angka 3, tidak setuju dengan angka 2, dan sangat tidak setuju dengan angka 1 .

\section{HASIL DAN PEMBAHASAN}

Ada 100 responden yang berhasil diambil pernyataan tentang harapan dan kenyataan tentang jasa parkir di Royal Plaza. Semua adalah pengguna jasa parkir dari kelompok kendaraan mobil. Waktu yang diperlukan untuk memperoleh pernyataan 100 responden adalah 9 hari. Profil responden terbagi menjadi beberapa karakteristik.

Berdasarkan jenis kelamin, ada $31 \%$ pengendara wanita; dan $69 \%$ pengendara pria. Berdasarkan usia, ada $11 \%$ berusia di bawah 20 tahun; $28 \%$ berusia antara 20 - 29 tahun; $49 \%$ berusia antara 30 - 40 tahun; dan sisanya berusia lebih dari 40 tahun. Frekuensi kunjungan ke Royal Plaza adalah 28\% pada intensitas sering sekali; $19 \%$ intensitas sering; $20 \%$ intensitas cukup sering; $23 \%$ cukup jarang; dan $10 \%$ jarang.

Validitas butir pertanyaan ditentukan dengan membandingkan setiap angka indikator dengan keseluruhan angka indikator variabel. Ketentuan minimal untuk dianggap sah merupakan nilai $r$ hitung $>$ dari 0,3. Hasil seperti pada tabel 1 yang menunjukkan tidak ada butir yang digugurkan atau semua valid.

Tabel 1. Uji Validasi Penilaian Kinerja dan Tingkat Kepentingan

\begin{tabular}{cccccc}
\hline \multicolumn{2}{c}{ Penilaian Kinerja } & \multicolumn{3}{c}{ Tingkat Kepentingan } \\
\hline \multirow{2}{*}{ tangibles } & $\mathrm{X} .1 .1$ & 0,478 & tangibles & $\mathrm{X} .1 .1$ & 0,512 \\
& $\mathrm{X} .1 .2$ & 0,542 & & $\mathrm{X} .1 .2$ & 0,593 \\
reliability & $\mathrm{X} .2 .1$ & 0,434 & reliability & $\mathrm{X} .2 .1$ & 0,481 \\
& $\mathrm{X} .2 .2$ & 0,306 & & $\mathrm{X} .2 .2$ & 0,457 \\
responsiveness & $\mathrm{X} .3 .1$ & 0,452 & responsiveness & $\mathrm{X} .3 .1$ & 0,469 \\
& $\mathrm{X} .3 .2$ & 0,387 & & $\mathrm{X} .3 .2$ & 0,419 \\
assurance & $\mathrm{X} .4 .1$ & 0,361 & assurance & $\mathrm{X} .4 .1$ & 0,383 \\
empathy & $\mathrm{X} .4 .2$ & 0,419 & & $\mathrm{X} .4 .2$ & 0,426 \\
& $\mathrm{X} .5 .1$ & 0,445 & empathy & $\mathrm{X} .5 .1$ & 0,496 \\
& $\mathrm{X} .5 .2$ & 0,507 & & $\mathrm{X} .5 .2$ & 0,562 \\
\hline
\end{tabular}

Uji reliabilitas guna mengenali kestabilan alat ukur dengan metode Cronbach's Alpha, serta batasan dasar sebesar 0, 6. Angka CA Berlandaskan hasil percobaan keabsahan, dikenal kalau evaluasi kinerja sebesar 0, 836 serta tingkatan kebutuhan 0, 805. Dua variabel itu mempunyai angka $r$ lebih besar dari 0,6 . Tingkat kepuasan pelanggan diukur dengan Customer Satisfaction Index dengan pertimbangan tingkat kepentingan dan kinerja jasa. Hasil CSI dengan tingkat kesesuaian di tabel 2. 
Tabel 2. Tingkat Kesesuaian

\begin{tabular}{|c|c|c|c|c|c|}
\hline \multirow{2}{*}{ No } & \multirow{2}{*}{ Atribut } & \multicolumn{2}{|c|}{ Total Skor } & \multirow{2}{*}{ Kesesuaian } & \multirow{2}{*}{ Keputusan } \\
\hline & & Kepentingan & Kepuasan & & \\
\hline X.1.1 & $\begin{array}{l}\text { Akses lokasi parkir dekat dengan pusat } \\
\text { perbelanjaan }\end{array}$ & 475 & 424 & 89,26 & $\mathrm{H}$ \\
\hline X.1.2 & $\begin{array}{l}\text { Lokasi parkir membuat tetap mengunjungi Royal } \\
\text { Plaza }\end{array}$ & 427 & 326 & 76,35 & A \\
\hline X.2.1 & Tarif parkir terjangkau & 402 & 308 & 76,62 & A \\
\hline X.2.2 & Tarif parkir sesuai dengan kualitas pelayanan & 423 & 327 & 77,30 & A \\
\hline X.3.1 & $\begin{array}{c}\text { Tidak pernah keluar area parkir karena tidak } \\
\text { mendapatkan tempat parkir }\end{array}$ & 468 & 382 & 81,62 & A \\
\hline X.3.2 & $\begin{array}{c}\text { Tidak pernah berputar-putar dalam area parkir } \\
\text { untuk mencari tempat parkir }\end{array}$ & 476 & 393 & 82,56 & $\mathrm{H}$ \\
\hline X.4.1 & $\begin{array}{l}\text { Parkir sudah memenuhi standar keamanan seperti } \\
\text { adanya cctv }\end{array}$ & 470 & 441 & 93,83 & $\mathrm{H}$ \\
\hline $\mathrm{X} .4 .2$ & Kendaraan saya akan terparkir dengan aman & 495 & 429 & 86,67 & $\mathrm{H}$ \\
\hline X.5.1 & $\begin{array}{c}\text { Tempat parkir memudahkan saya mengunjungi } \\
\text { Royal Plaza }\end{array}$ & 451 & 351 & 77,83 & A \\
\hline X.5.2 & $\begin{array}{c}\text { Saya tidak kesulitan jika membawa barang } \\
\text { banyak ke tempat parkir }\end{array}$ & 439 & 345 & 78,59 & A \\
\hline & Nilai Rata-Rata & & 82 , & $6 \%$ & \\
\hline
\end{tabular}

Berdasarkan tabel 2 adalah antara tingkatan kepuasan dengan tingkat kepentingan atribut- atribut jasa parkir hingga terbuat sesuatu evaluasi khusus yang menjadi dasar guna menjaga prestasi pelayanan yang bagus ataupun wajib melaksanakan koreksi kepada layanan yang sudah ada. Batasan dari pengumpulan keputusan ialah sebesar $82 \%$ dengan metode memakai dorong ukur ialah angka pada umumnya tingkatan kesesuaian atribut pertanyaan. Dasar dari keputusan itu merupakan apabila tingkatan kesesuaian $<82 \%$ hingga dicoba perbaikan atau action (A), serta apabila tingkatan kesesuaian $\geq 82 \%$ hingga dilakukan upaya guna menjaga hasil atau hold $(\mathrm{H})$. Dari tabel 2 diketahui ada enam butir yang harus dilakukan perbaikan, dan empat butir yang harus dipertahankan. Empat butir yang dipertahankan prestasi terdiri dari satu unsur responsiveness, dan dua unsur assurance.

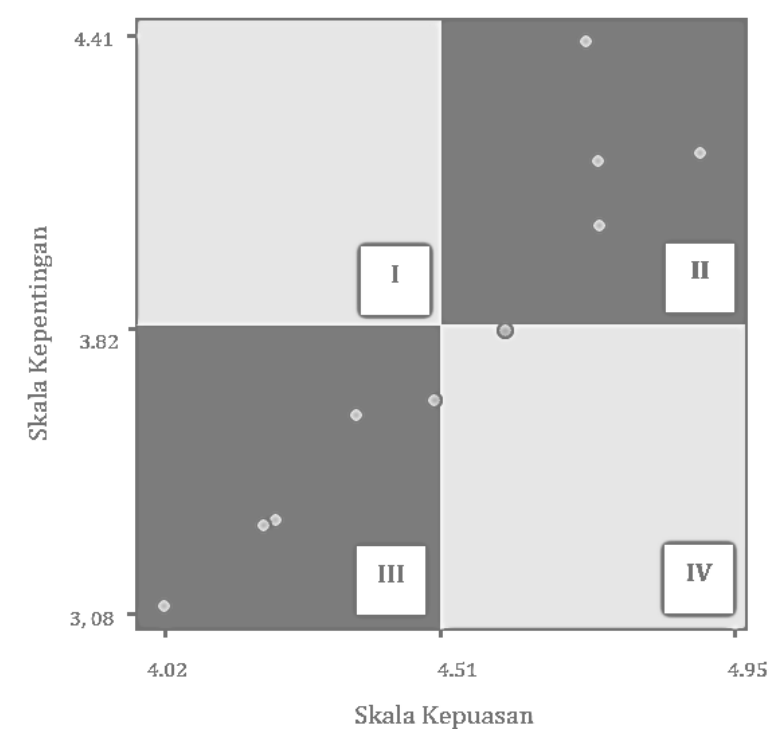

Gambar 1. Diagram tingkat kepuasan pengguna jasa

Penemuan pada penempatan di kuadran II membuktikan saran untuk menjaga perolehan dimana pada kuadran ini mempunyai tingkatan angka yang sangat besar bagus dari bidang tingkatan kebutuhan klien serta tingkatan kinerjanya, akibatnya atribut yang terletak pada kuadran II bisa dibilang terjamin serta wajib dipertahankan kinerjanya.

Kuadran III membuktikan rasio prioritas yang kecil, dimana atribut ini dikira kurang berarti pengaruhnya untuk konsumen jasa serta pada faktanya kinerjanya tidak sangat eksklusif. Untuk pihak pengelola hendaknya butuh diperhitungkan lagi pada ciri ini sebab ciri yang masuk pada kuadran ini dikira kurang berarti serta kurang memenuhi untuk konsumen jasa parkir.

Kuadran IV merupakan melampaui batas, ini membuktikan kalau atribut pada kuadran ini ditaksir mempunyai tingkatan kebutuhan yang kecil tetapi tingkatan kinerja yang diberikan besar. Diduga kurang berarti namun jasa yang diberikan sungguh memenuhi pengguna. 
Hasil ini seharusnya ditindaklanjuti dengan perbaikan kinerja dengan impian bila pengguna akan mempunyai rasa puas atau bisa sangat puas sehingga fasilitas parkir menjadi salah satu daya tarik bagi pengunjung Royal Plaza. Tidak hanya itu dengan tercapainya kepuasan konsumen dengan cara maksimal hingga mereka jadi tidak sensitif kepada ekskalasi harga karcis parkir serta bisa membagikan pendapat yang bagus mengenai keberadaaan pusat pembelanjaan Royal Plaza.

\section{KESIMPULAN}

Temuan dari studi ini adalah responden pada umumnya cenderung telah mencapai kepuasan dalam tingkatan yang baik. Ada beberapa atribut yang perlu dikembangkan lebih baik lagi seperti tarif parkir yang harus disesuaikan dengan manfaat yang diperoleh oleh pengguna jasa parkir, lokasi parkir harus menjadi daya tarik disertai dengan pelayanan yang lebih baik. Ada upaya untuk menghindari pengunjung tidak memperoleh tempat parkir karena keterpenuhan dan padatnya tempat parkir. Selain itu juga ada tugas untuk memastikan pengunjung tidak kesulitan membawa barang banyak dari dan ke tempat parkir. Sedangkan atribut yang telah memuaskan pengguna adalah akses lokasi parkir telah dekat dengan pusat perbelanjaan dan mereka tidak pernah berputar-putar dalam area parkir untuk mencari tempat parkir. Parkir sudah memenuhi standar keamanan seperti adanya cctv dan mereka merasa kendaraan akan terparkir dengan aman. Atribut-atribut tersebut harus dipertahankan kinerjanya agar tetap menjadi unsur utama pembentuk dari kepuasan pengguna jasa parkir. Pihak pengelola bisa melaksanakan koreksi kualitas bersumber pada atribut- atribut yang telah diukur selaku usaha guna menghasilkan kepuasan pelanggan yang maksimal. Pengelola serta wajib menghasilkan serta mengatur sesuatu sistem yang bagus guna menyediakan tanah parkir yang lebih besar sebagai akibat dari pertambahan jumlah pengunjung di setelah itu hari. Pihak pengelola Royal Plaza dan mitra perlu mengembangkan tata kelola parkir yang lebih baik karena ini adalah salah satu faktor daya tarik peningkatan jumlah kunjungan. Ini juga merupakan determinan dari kepuasan pengunjung di Royal Plaza. Pihak pengelola dan mitra harus terus mengembangkan sistem pengaturan parkir yang efisien guna memberikan rasa aman dan rasa aman kepada pengguna jasa parkir sebagai salah satu fasilitas yang ada. Penetapan standar pelayanan perparkiran dan pengawasan terhadap pelaksanaan memerlukan manajemen yang efektif serta dukungan sumber daya manusia yang andal. Untuk membentuk keandalan sumber daya manusia dengan memberikan pembinaan petugas parkir di lapangan serta memberikan pembekalan keterampilan seperti keterampilan komunikasi dan tata letak ruang. Kemampuan melayani juga diperlukan karena pengguna jasa parkir seharusnya terpenuhi harapan mereka saat menggunakan jasa tersebut. Dengan begitu, para petugas yang ikut serta akan jadi lebih mengerti tentang manajemen jasa perparkiran yang efisien alhasil akibat sosial yang ditimbulkan sebab kondisi perparkiran itu bisa diminimalisir semacam ketidakpuasan wisatawan di Royal Plaza. Survei kepuasan pengguna jasa parkir di Royal Plaza harus dilakukan secara berkesinambungan agar memperoleh identifikasi sejauh mana harapan pengguna telah terpenuhi dan sebagai dasar dari perbaikan sistem maupun pengembangan menjadi lebih baik dalam pengelolaan. Keterlibatan teknologi diperlukan lebih jauh untuk memaksimalkan manajemen perpakiran. Ini menjadi penting karena manajemen yang bagus hendak mengurangi permasalahan semacam antrean kendaraan yang setelah itu sungguh berpotensi memunculkan kemacetan di pintu masuk ataupun loket. Teknologi yang lebih mutahir dibutuhkan guna mengenali sebagai sistem serta mulai meninggalkan sistem karcis yang membutuhkan waktu relatif lumayan lama yang pada kesimpulannya memunculkan antrean panjang. Guna itu diperlukan sistem pengenalan kendaraan yang lebih cepat serta efisien. Pengenalan dengan cara otomatis dengan membaca plat no kendaraan ialah pengganti yang dipilih.

\section{REFERENCES}

Anderson, T.W. \& L.L. Olsen. (2008). The Impact of Customers' Perception of Varying Degrees of Customer Service on Commitment and Perceived Relative Attractiveness, Managing Service Quality, 18(4), 309-328.

Cronin, J.J \& S.A. Taylor. (1992). Measuring Service Quality: A Re-examination and Extension, Journal of Marketing, 56(3), 5668.

Darmawan, D. (2004). Pengaruh Persepsi Kualitas Layanan, Citra Merek, dan Kepuasan Nasabah terhadap Respon Perilaku Nasabah, Jurnal Ilmiah Manajemen dan Akuntansi, 1(1), 33-47.

Darmawan, D. (2004). Pengaruh Kualitas Layanan terhadap Kepuasan Penumpang Kapal Feri Penyeberangan Ujung-Kamal, Jurnal Ekonomi dan Bisnis, 8(2), 39-44.

Darmawan, D. (2009). Pemasaran Jasa, IntiPresindo Pustaka, Bandung

Darmawan, D. (2019). The Effect of Customer Satisfaction on Trust and Customer Loyalty, Management \& Accounting Research Journal, 3(2), 1-8.

Darmawan, D. (2019). Kualitas Produk, Kesadaran Merek dan Harga serta Pengaruhnya terhadap Kepuasan Pelanggan, Jurnal Administrasi Bisnis, 8(2), 75-88.

Darmawan, D. (2021). Pencapaian Kepuasan dan Loyalitas Pelanggan melalui Strategi Pemasaran Berdasarkan Pengalaman (Studi Kasus Pelanggan Rumah Makan Ayam Bakar Wong Solo di Mojokerto), Jurnal Manajemen, Bisnis, dan Kewirausahaan, 1(1), 1-13.

Djati, S. Pantja \& D. Darmawan. (2004). Pengaruh Kesan Kualitas Layanan, Harga dan Kepuasan mahasiswa PTS terhadap Minat Mereferensi Kampusnya, Jurnal Widya Manajemen dan Akuntansi, 4(2), 190-204.

Johnson, M.D., A. Gustafsson, \& T.W. Andreassen. (2001). The Evolution and Future of National Customer Satisfaction Index Models, Journal of Economic Psychology, 22(2), 217-45.

Kotler, P., \& G. Armstrong. (2016). Principles of Marketing (16th ed.). Pearson Education Limited, Boston. 
Ekonomi, Keuangan, Investasi dan Syariah (EKUITAS)

Vol 3, No 2, November 2021, Hal 307-311

ISSN 2685-869X (media online)

DOI 10.47065/ekuitas.v3i2.1167

Kotler, P. \& K.L. Keller. (2016). Marketing Management (15th ed.). Pearson Education Limited, Boston.

Lovelock, Christopher H. (1996). Service Marketing, 3rd edition, Prentice-Hall, London.

Masitoh, D., D. Darmawan \& E. A. Sinambela. (2017). The Effect of Service Quality and Trust on Customer Loyalty of Warung Apung Rahmawati of Mojokerto Branch, Jurnal Agrimas, 1(2), 107-114.

Parasuraman, A., Valarie A. Zeithaml, \& Leonard L. Berry. (1985). A Conceptual Model of Service Quality and Its Implications for Future Research, The Journal of Marketing, 49(4), 41-50.

Zameer, Hashim., Anam Tara, Uzma Kausar, \& Aisha Mohsin. (2015). Impact of Service Quality, Corporate Image and Customer Satisfaction Towards Customers' Perceived Value in the Banking Sector in Pakistan, International Journal of Bank Marketing, 33(4), 442-456.

Zeithaml, Valarie A., Leonard L. Berry, \& A. Parasuraman. (1996). The Behavioral Consequences Of Service Quality, Journal of marketing, 60, 31-46. 